\title{
Da constitucionalidade da internação hospitalar na modalidade diferença de classe
}

\section{Julio Flavio Dornelles de Matos ${ }^{1}$, Cristiane Paim ${ }^{2}$}

A internação hospitalar na modalidade diferença de classe consiste na possibilidade de o paciente optar por melhores acomodações e/ou tratamento médico, não abrangidos pelo Sistema Único de Saúde (SUS), com o pagamento pecuniário da diferença de custos pelo próprio paciente ou pelo seu responsável.

No Brasil, tem-se o Sistema Único de Saúde de acordo com o art. 198 da Constituição Federal de 1988 que é composto por hospitais públicos e complementado pela rede de hospitais privados, sejam eles com ou sem fins lucrativos, conveniados e/ou contratados ao SUS, recebendo contraprestação do Estado por serviços prestados aos cidadãos, conforme $\S 1^{\circ}$, do art. 199 da CF/88. É nesses hospitais privados que ocorreria a possibilidade de opção pela diferença de classe, pois os hospitais públicos, pelas suas naturezas, em regra, não oferecem tratamento diferenciado daqueles já dispostos ao SUS.

Sendo assim, na internação hospitalar na modalidade diferença de classe, o paciente poderia optar por acomodações com padrão de conforto diferente do oferecido pelo SUS, como, por exemplo, a troca da enfermaria por um quarto privativo, e/ou ter atendimento por profissional de sua escolha, com o pagamento ajustado entre o paciente e o profissional.

Ocorre que existem obstáculos legais que vão expressamente contra a diferença de classe, tais como o item 2.1 da Resolução no 283, de 30 de agosto de 1991, do extinto Instituto Nacional de Assistência Médica da Previdência Social (INAMPS) que veda a complementaridade a qualquer título à unidade assistencial.

Além disso, alega-se a violação do princípio da isonomia e do direito universal à saúde, um dever do Estado, garantidos no art. 5ํㅗ caput, inciso I, e no art. 196, da

\footnotetext{
${ }^{1}$ Advogado, especialista em gestão empresarial, Presidente da Federação das Santas Casas e Hospitais Beneficentes, Religiosos e Filantrópicos do Rio Grande do Sul, Porto Alegre, Brasil. E-mail: juridico@federacaors.org.br

${ }_{2}^{2}$ Advogada, especialista em direito processual, Vice-Presidente da Comissão Especial de Saúde da Ordem dos Advogados do Brasil, Seccional Rio grande do Sul, Porto Alegre, Brasil. E-mail: juridico@federacaors.org.br
} 
Constituição. Ainda, os artigos $2^{\circ}, \S 1^{\circ}$, e $7^{\circ}$, incisos I e IV da Lei Orgânica da Saúde (Lei nํ. 8.080, de 1990), estabelecem que o princípio da universalidade de acesso ao serviço de saúde conjuga-se com a igualdade à assistência, sem preconceitos ou privilégios de qualquer espécie.

Diante do exposto, levanta-se a questão da constitucionalidade da internação hospitalar na modalidade diferença de classe. Indaga-se: pode o beneficiário do SUS, como sistema universal, optar por acomodação diferenciada da oferecida para todos, mediante o pagamento da diferença?

A Constituição Federal de 88 é uma constituição cidadã, que busca estabelecer equilíbrio entre os direitos individuais, fundamentais e os públicos, inclusive protegendo a igualdade, a cidadania, a segurança, a propriedade privada e a dignidade da pessoa humana. Por meio da leitura de nossa Carta Magna, verifica-se que ela tende à proteção do homem, sem apresentar regra geral de limitações aos direitos, liberdades e garantias fundamentais. Não há na Constituição uma escala hierárquica de valores ou de princípios, ao contrário, ela equipara interesses coletivos e individuais. Nem mesmo há previsão sobre o princípio da supremacia do interesse público sobre o privado.

O que se observa na Carta Magna de 88 é a ideia de unicidade entre direitos, interesses e valores, sem a prevalência de um ou de outro. Portanto, verifica-se que inexiste hierarquia entre eles.

Destarte, não há como simplesmente resolver um conflito de interesses com a aplicação do princípio da supremacia do interesse público.

Os princípios têm como pressuposto a harmonização e adequação das normas, o que não se observa com a aplicação do princípio da supremacia do interesse público. Este lembra o Estado Absoluto, em que o poder do governo era ilimitado. Isso porque tal princípio trata-se de uma regra de prevalência que impede o sopesamento de interesses.

Conforme já mencionado, os interesses coletivos e individuais possuem o mesmo objetivo, o que os torna inseparáveis. De tal modo, a prevalência de um sobre o outro resta prejudicada, já que ambos trabalham juntos.

Não se pretende aqui negar a existência de situações em que há conflito entre os interesses coletivos e individuais, mas sim, demonstrar que em tais casos deve haver um juízo de ponderação e não a aplicação da resposta mais fácil, que é o princípio da supremacia do interesse público, o qual não mais supre as necessidades atuais. 
A ideia do Estado Democrático descrita na Constituição Federal de 88 é a de que não deve haver prevalência entre interesses, mas sim uma unidade entre eles. Nesse sentido, o princípio da proporcionalidade vem de encontro às disposições constitucionais, visto que tenta harmonizar os interesses em confronto, sem prejuízo de um ou de outro.

Sendo assim, na situação de conflito entre um interesse coletivo e um individual, deve ser realizada análise das normas e princípios em questão, com a utilização da ponderação a fim de se alcançar uma solução que não ofenda os direitos fundamentais.

Ao encontro desse entendimento tem-se a ementa do RE 226.835-6 do Rio Grande do Sul, citada nos votos dos relatores nos RE 261.268-5 e 207.970-7, de onde se extrai um dos principais argumentos utilizados nos casos de diferença de classe, a partir da alegação de que o Estado não pode impor obstáculos ao direito à saúde, garantido na Constituição Federal, in verbis:

O direito à saúde, como está assegurado na Carta, não deve sofrer embaraços impostos por autoridades administrativas, no sentido de reduzilo ou de dificultar o acesso a ele.

A partir do argumento acima, pode-se concluir que a universalidade da saúde consiste no fornecimento igualitário dos serviços do SUS, ou seja, leitos oferecidos em igualdade de condições. Deste modo, o direito à saúde, um dever do Estado, resume-se a um mínimo que deve ser oferecido e quem quiser pode optar pela diferença de classe. $\mathrm{O}$ oposto seria o Estado obrigar as pessoas que recorrem ao SUS a se submeterem a um tratamento ' $\mathrm{x}$ ' igual para todos. É neste sentido que o Ministro Ilmar Galvão (Relator) discursa no RE 226.835-6 (fl. 451), in verbis:

Impor-se generalidade de situações configura lesão à ordem natural e cerceia o exercício de direito ao melhor tratamento de saúde, conforme provimento financeiro do interessado.

Esse outro argumento exaustivamente utilizado também foi encontrado no RE 226.835-6 do Rio Grande do Sul, citado nos votos dos relatores nos RE 261.268-5 e 207.970-7 e procura refutar a alegação de violação do princípio da igualdade (art. 5을 $\mathrm{CF} / 88)$, in verbis:

Inocorrência de quebra da isonomia: não se estabeleceu tratamento desigual entre pessoas numa mesma situação, mas apenas facultou-se atendimento diferenciado em situação diferenciada, sem ampliar direito previsto na Carta e sem nenhum ônus extra para o sistema público. 
Considerando-se que o serviço do SUS não é imposto, mas sim fornecido, existe a possibilidade do paciente optar por tratamento e/ou acomodação superiores aos tutelados pelo SUS, com a diferença de custos pagos pelo paciente para não onerar os cofres públicos. Deste modo, a distinção não seria criada pelo poder público, mas pela própria condição financeira do paciente o que significa dizer que, sob o enfoque dos direitos fundamentais é possível de se adotar a diferença de classe nas internações hospitalares, desde que adotado o Princípio da Proporcionalidade e considerados, fundamentalmente, aspectos como: o acesso regulado conforme as normas do sistema e o estabelecimento de parâmetros mínimos e máximos de honorários médicos e de serviços hospitalares a serem cobrados dos pacientes.

Ao concluir, afastada questões de naturezas ideológicas, com a prevalência do bom senso e com base no ordenamento jurídico brasileiro, é possível afirmar-se que a modalidade da diferença de classe no SUS não contraria a Constituição Federal e, mais do que o eventual interesse dos prestadores de serviços, deve-se considerar o direito de escolha do cidadão beneficiário do Sistema, sem abdicar dele. Ao se adotar o princípio da proporcionalidade, verifica-se a adequação e a compatibilidade dos direitos individuais e coletivos nesta situação.

\section{Referências bibliográficas}

BRASIL. Constituição (1988). Constituição da República Federativa do Brasil. Brasília, DF: Senado Federal, 2008.

BRASIL. Lei n. 8.080, de 19 de setembro de 1990. Dispõe sobre as condições para a promoção, proteção e recuperação da saúde, a organização e o funcionamento dos serviços correspondentes e dá outras providências. Brasília, 19 set. 1990. Disponível em: http://www.planalto.gov.br/ccivil 03/leis//8080.htm Acesso em: 17 de nov. 2014.

BRASIL. Rio Grande do Sul. Superior Tribunal de Justiça. Recurso Especial n. 226.835-6.

BRASIL. Rio Grande do Sul. Superior Tribunal de Justiça. Recurso Especial n. 261.268-5.

BRASIL. Rio Grande do Sul. Superior Tribunal de Justiça. Recurso Especial n. 207.970-7.

BRASIL. Resolução no. 283, de 30 de agosto de 1991. Estabelece em seu artigo 2.1 que a autorização de internação hospitalar AlH garante a gratuidade total da assistência prestada, sendo vedada a profissionais e a universidades assistenciais, públicas ou privadas, contratadas ou conveniadas, a cobrança ao paciente ou seus familiares, de complementaridade de qualquer título. INAMPS. Brasília, 30 ago. 1991. 
HO, C. Recepção da Internação Hospitalar na Modalidade "Diferença de Classe" pelo STF. Monografia. Direito Público - Escola de Formação de 2005. Sociedade Brasileira de Direito Público. São Paulo, 2005. 